\title{
0 que deve aprender o professor de História? Reflexões sobre aprendizagem, ensino e formação docente inicial ${ }^{1}$
}

\author{
Which pasts are taught in the present? Some reflections on History, \\ teaching and teacher training
}

\author{
¿Qué debe aprender el profesor de historia? Reflexiones sobre el \\ aprendizaje, la enseñanza y la formación del profesorado
}

\section{Erinaldo Vicente Caualcanti ${ }^{2}$}

Universidade Federal do Sul e Sudeste do Pará, Programa de Pós-graduação em História, Professor e Coordenador.

https://orcid.org/0000-0002-9912-5713

Resumo: 0 artigo faz uma reflexão sobre as principais temáticas de estudo que são ensinadas e aprendidas na formação inical do professor de História. Analisa quais temas aparecem nas disciplinas obrigatórias sobre o ensino de história para compreender o lugar ocupado pelos debates sobre a educação histórica. Para tanto, utilizo as matrizes curriculares dos cursos oferecidos nas universidades federais, localizadas na região Amazônica do Brasil, como uma opção para problematizar o que se ensina e se aprende na formação do professor dessa área. As análises demonstram que as licenciaturas pesquisadas não têm priorizado as reflexões sobre o ensino de História e, praticamente, têm ignorado o debate sobre educação histórica durante o período de formação inicial dos professores.

Palavras-chave: Ensino de História. Educação histórica. Formação docente.

Abstract: The article brings a reflection on the main themes of study that are taught and learned in the initial formation of the history teacher. It analyzes which themes appear in the compulsory subjects of history teaching to understand the place occupied by debates on historical education. To this end, curriculum matrices of the courses offered at federal universities located in the Amazon region of Brazil were used as an option to discuss what is taught and learned in the education of teachers in this field. The analysis show that the undergraduate degrees researched have not prioritized the reflections on

Gostaria de agradecer às importantes críticas e sugestões dos membros pesquisadores do laboratório e grupo de pesquisa iTemnpo (Interpretação do Tempo: ensino, memória, narrativa e política) quando o texto foi debatido em nossos encontros. Doutor e Mestre em História pela Universidade Federal de Pernambuco. 
the teaching of history and, practically, have been ignoring the debate on historical education during the period of initial teacher education.

Keywords: History teaching. Historical education. Teacher training.

Resumen: El artículo reflexiona sobre los principales temas de estudio que se enseñan y aprenden en la formación inicial del profesor de historia. Analiza qué temas aparecen en las asignaturas obligatorias de la enseñanza de la historia para comprender el lugar que ocupan los debates sobre educación histórica. Con este fin, utilizo las matrices curriculares de los cursos ofrecidos en las universidades federales, ubicadas en la región de Amazónica de Brasil, como una opción para discutir lo que se enseña y aprende en la educación de los maestros en esta área. Los análisis muestran que los cursos universitarios investigados no han priorizado las reflexiones sobre la enseñanza de la historia y, prácticamente, han ignorado el debate sobre la educación histórica durante el periodo de formación inicial del profesorado.

Palabras clave: Enseñanza de historia. Educación histórica. Formación del profesorado.

Recebido em 22 de agosto de 2019

Aceito em 23 de dezembro 2019

Publicado em 15 de junho de 2020

Refletir sobre o uso prático do saber histórico é um requisito básico da ciência da história. E é uma exigência dos especialistas, para que não confundam o fundamento de sua ciência na vida com uma torre de marfim perdida no espaço.

(Jörn Rüsen)

\section{CONSIDERAÇÕES INICIAIS}

Gostaria de iniciar a reflexão mencionando o lugar da minha escrita, afinal todos nós escrevemos de um lugar, que é marcado pela pluralidade de ideias, concepções, paradoxos e dissensos até. Minha trajetória de pesquisa e escrita é marcada pelo desafio de ter experienciado a produção de um texto de livro didático. ${ }^{3}$

0 presente artigo, portanto, insere-se nesse percurso e espaço de reflexão e se propõe a fazer uma análise sobre algumas questões que envolvem a História e seu ensino, compreendidos como um campo de disputas e um lugar de saber/poder, como um lugar de 
formação docente. Apresento algumas reflexões sobre certas temáticas que são vivenciadas em termos de oferta de disciplinas nas licenciaturas em História oferecidas pelas universidades federais localizadas na região amazônica do Brasil. Problematizo, de maneira específica, como as discussões sobre aprendizagem histórica aparecem nos cursos analisados. Para tanto, utilizo as matrizes curriculares das licenciaturas - também chamadas de Projeto Político Pedagógico (PPP) ou Projeto Político Curricular (PPC) - como uma opção para problematizar alguns objetos de estudo, ensino e aprendizagem nos referidos cursos. As análises demonstram que as licenciaturas pesquisadas têm tematizado, predominantemente, a história europeia e mantêm a clássica periodização quadripartite da História. Além disso, pouco tem se investido nas reflexões sobre ensino de História e, menos ainda, sobre aprendizagem e educação histórica.

As pesquisas que venho desenvolvendo sinalizam que a História, como ciência e espaço de formação de professores, no Brasil, não tem demonstrado muito interesse com relação ao ensino da própria área (CAVALCANTI, 2018a, 2018b, 2019). Sobre o período de formação inicial, a História tem praticamente ignorado o debate sobre os fundamentos epistemológicos acerca do processo de aprendizagem histórica.

Por aprendizagem histórica me refiro a um conjunto de habilidades cognitivas que permite ao sujeito aprendiz compreender a História - individual e coletiva - como construção humana no tempo. Conforme defende o historiador alemão Rüsen (2011a), trata-se da capacidade interpretativa relacionada ao tempo, que permite ao aprendiz experimentar de forma significativa as relações temporais. Em suas palavras, "[...] o aprendizado histórico pode, portanto, ser compreendido como um processo mental de construção de sentido sobre a experiência do tempo através da narrativa histórica, na qual as competências para tal narrativa surgem e se desenvolvem." (RÜSEN, 2011b, p. 43). E, segundo esse autor, a Didática da História é a área em que essas competências são analisadas. Em suas palavras, "[..] é a ciência da aprendizagem histórica." (RÜSEN, 2015, p. 248).

Nesse sentido, a aprendizagem histórica é capaz de desenvolver o senso de orientação nas relações cotidianas do sujeito que aprende e, para tanto, mobiliza a capacidade interpretativa acerca das experiências vivenciadas. Assim, a aprendizagem histórica é uma interpretação relativa ao tempo, capaz de promover formas de comportamento, maneiras de atuação e formas de ver, sentir, perceber, agir e ser. Ou seja, ela é orientação no e com o tempo.

Para Jörn Rüsen, o ensino da História precisa ter finalidade de orientação na vida prática de homens e mulheres. Aprender História, portanto, consiste em desenvolver uma percepção interpretativa capaz de se constituir como força que concorre para as tomadas de decisão no pensar e agir cotidianos. Nesses termos, questiona o historiador: "[...] qual é a utilidade de um vasto conhecimento histórico, quando ele é ensinado apenas como algo a ser decorado e sem nenhum impacto orientativo?" (RÜSEN, 2011a, p. 84). Ao dialogarem com Rüsen, Schmidt e Cainelli (2015, p. १25) enfatizam que "[...] aprender história significa aprender a narrá- 
la, de tal forma que, nela e com ela, possamos encontrar o reconhecimento, sem o qual não gostaríamos de ser ou poder ser."

As reflexões sobre aprendizagem histórica parecem permanecer estrangeiras para a maioria dos estudantes de graduação durante sua formação nas universidades federias do Brasil. As matrizes curriculares, pelas quais são formados os professores de História, têm disponibilizado pouco tempo para se refletir sobre o ensino dessa disciplina e, menos ainda, para se debater e compreender as relações que envolvem as capacidades cognitivas pelas quais se aprende historicamente. É possível afirmar, pelos currículos dos cursos de formação docente, que uma larga parcela dos professores formados nesses cursos desconhece o debate especializado sobre a aprendizagem histórica.

\section{SITUANDO O OBJETO DE ESTUDO}

É importante registrar que a formação docente é amplamente tematizada por diferentes pesquisadores e por distintos objetos de investigação, o que não significa que essa seja uma temática esgotada. Pelo contrário. As reflexões da literatura especializada ${ }^{4}$ oferecem valiosas análises para mostrar a pluralidade de abordagens e a importância que a temática merece, sobretudo no momento atual em que a educação e a formação dos professores, no Brasil, vêm sendo atacadas cotidianamente.

Nessa perspectiva, são importantes as reflexões de Tardif (2014) quando postula que os saberes e as práticas docentes são múltiplos e heterogêneos. Por conseguinte, não existe relação de determinismo entre os documentos prescritos e as ações dos professores no exercício da docência. Nessa chave de interpretação, também são valiosas as contribuições de Monteiro (2007) ao defender que existe uma relativa autonomia nas atividades desenvolvidas pelos professores no exercício da sua profissão. Uma autonomia construída a partir da trajetória pessoal e profissional, das referências sociais e culturais partilhadas pelos professores.

A aprendizagem histórica é objeto privilegiado no âmbito das reflexões da educação histórica. Os estudos, nesse espaço de produção de conhecimento, não são recentes, conforme apontam Schmidt e Garcia (2006), Ramos e Cainelli (2015) e Barca (2006). №

4 Diferentes autores têm contribuindo com importantes reflexões que analisam a formação docente do professor de História, problematizando-a a partir de diferentes objetos de estudo, como o livro didático, currículo, novas tecnologias, aprendizagem histórica e tempo presente. Para mencionar apenas alguns desses autores: Arroyo (2013), Caimi (2015), Rocha, Reznik e Magalhães (2017), Monteiro e Rocha (2015), Monteiro (2013, 2015), Oliveira, Cainelli e Oliveira (2008), Pereira e Seffner (2008), Schmidt, Barca e Martins (2011), Schmidt (2017, 2019), Rüsen (2010, 2011a, 2011b, 2011c), Fonseca (2008) e Silva (2017). 
entanto, no que tange ao Brasil - e, de forma específica, à História como área de conhecimento especializado -, as reflexões ainda são tímidas, mesmo que se verifique um crescimento nos últimos anos (EVANGELISTA; TRICHES, 2006). Pioneiro nesse debate e referência nas pesquisas especializadas, o Laboratório de Pesquisa em Educação Histórica da UFPR (Lapeduh) tem ganhado destaque e reconhecimento internacional. Liderado pela professora e pesquisadora Maria Auxiliadora Schmidt, o Lapeduh tem conduzido um conjunto de ações envolvendo pesquisas de graduação, mestrado e doutorado, além de cursos e seminários especializados.

Nesse sentido, Maria Auxiliadora e Ana Claudia Urban ressaltam a importância e o crescimento das reflexões acerca da educação histórica, como lugar teórico de significativa contribuição para o processo de formação docente. Para elas, "a Educação Histórica tem se constituído, por exemplo, como teoria e aplicação à educação em geral e ao ensino de História, em particular, de princípios da cognição histórica, pois parte do pressuposto de que existe uma cognição própria em História." (SCHMDT; URBAN, 2018, p. 9). Conforme ressaltam as autoras, as investigações acerca da aprendizagem histórica, como objeto de reflexão problematizado no âmbito da educação histórica, fundamentam-se, em larga medida, nas reflexões teóricas e epistemológicas operacionalizadas pelo historiador alemão Jörn Rüsen. ${ }^{5}$

Ao discutir alguns desafios do processo de ensinar e aprender História na formação inicial de professores, Cristiani Bereta e Luciana Rossato ressaltam o crescimento e a importância que as reflexões sobre educação histórica têm proporcionado. Para elas, o crescimento e o teor das pesquisas

[..] vêm ao encontro da constatação de que pouco avançaremos no ensino de História escolar e na própria formação de docentes para a educação básica se não considerarmos compreender a aprendizagem e os processos cognitivos envolvidos na elaboração das ideias históricas. (SILVA; ROSSAT0, 2013, p. 82).

Os desafios sobre a formação do professor ultrapassam as barreiras políticas do tempo e do espaço; é claro que, em cada momento e em cada lugar, os embates adquirem configurações específicas. Ao analisar a formação docente na América Latina, a professora Margarita Victoria Rodríguez destaca a atuação do Estado como agente promotor das principais mudanças implantadas a partir da década de 1990 no processo de globalização. Ela pontua as reformas implantadas no Chile, na Argentina e no Uruguai; mostra os desafios e as disputas sobre o processo de formação professoral e ressalta que ainda prevalece uma lacuna entre as instituições formadoras e as redes de ensino, e que "[...] se mantém uma grande distância entre os formadores dos docentes e a realidade escolar." (RODRíGUEZ, 2008, p. 19).

\footnotetext{
Jörn Rüsen é uma das principais referências, no campo da ciência histórica, no que tange ao debate sobre aprendizagem histórica. Para ampliar o debate, consultar: Rüsen (2011a, 2011b, 2011c, 2012).
} 
As reflexões ocorrem em diferentes países, que igualmente privilegiam um leque amplo de análise. Nessa perspectiva, são importantes as análises da professora Maria Paula Gonzalez ao considerar as relações entre as práticas docentes, a transmissão da história recente e o currículo na Argentina. Para ela, os professores mobilizam um conjunto variado de fatores no exercício da docência e, portanto, devem ser compreendidos "[...] como actores claves y a sus lecturas e interpretaciones del currículum como actos de resignificación activa." (GONZALEZ, 2008, p. 85).

A professora Maria do Céu de Melo (Universidade do Minho), ao analisar a formação do professor de História em Portugal, ressalta que a estrutura e a organização dos cursos universitários, na União Europeia, estão configuradas por meio do projeto vencedor que se encontra desenhado no Tratado de Bolonha (2001), o qual foi implantado em ritmos e formas variáveis. Ao analisar o mestrado profissional em ensino de História, ofertado nessa universidade, a professora pontua que é requisito obrigatório que o discente tenha formação no primeiro ciclo em História. Em seguida, ela mostra como se encontra configurada a estrutura curricular do período de formação inicial.

\footnotetext{
As unidades curriculares (UCs) (disciplinas) deste ciclo de estudos centramse em conhecimentos e competências nucleares da História, articulando de forma multidisciplinar tempos e espaços historicamente diversificados: Pré-História, Civilizações Antigas, Civilização Grega e Romana, Arte Clássica, Idade Média (Europa e Portugal), Descobrimentos e Expansão Portugueses, Arte Medieval, Idade Moderna (Europa e Portugal), Arte Moderna, Idade Contemporânea (Mundial e Portugal), Arte Contemporânea, e em temas de outras ciências sociais como a Geografia, Sociologia ou Antropologia (optativas). (MELO, 2015, p. 42).
}

0 professor Jean Pagès (2004), por sua vez, ao analisar o processo de formação docente do professor de História do ensino secundário, na Espanha, ressalta que o perfil desse profissional é uma construção histórica com variados e importantes elementos do campo de conhecimento epistemológico e historiográfico. Mas ele questiona se esses conhecimentos são suficientes para ensinar História no ensino médio - e, por que não, em toda a educação básica, para o caso do Brasil -, uma vez que a formação dos professores tem priorizado a aquisição dos conhecimentos específicos sobre os conteúdos a serem ensinados. Para Pagès (2004), ensinar é um ato de comunicação, e, portanto, quem ensina necessita ter formação para "essa comunicação" e conhecer os meios, os discursos, os instrumentos e o contexto em que se constrói a comunicação, ou seja, o ensino. Da mesma forma, é necessário para o comunicador conhecer o público a quem direciona sua comunicação, ou seja, o professor de História precisa ter conhecimento sobre o público a quem ele vai ensinar. Para Pagès (2004, p. 157), 
[...] lo que se comunica, este caso el conocimiento histórico, y cómo debemos comunicarlo para obtener aprendizajes. Y, además, el contexto en el que se realiza la comunicación, contexto que incluye desde las finalidades o propósitos educativos que la administración educativa otorga a los saberes escolares, el contexto social y cultural, hasta la institución en la que se realiza y la organización espacio-temporal en la que tiene lugar (organización del espacio aula y tiempo de duración de la comunicación).

0 que ensinar? Quais passados devem se fazer presentes em nosso cotidiano na sala de aula? Quais devem ser os objetos de estudo, reflexão e aprendizado nos cursos de formação de professores de História? 0 que deve, afinal, aprender um professor de História? Não há respostas definitivas para essas questões. Em cada momento, em cada instituição, em cada conjuntura política e histórica são construídas respostas para essas demandas. Nesses termos, é oportuno indagar: no tempo presente, o que deve aprender o professor de História da educação básica em seu período de formação inicial?

As discussões sobre formação de professor envolvem, diretamente, o debate sobre as matrizes curriculares. Não é objetivo deste artigo apresentar uma revisão bibliográfica sobre o currículo, pois exigiria outro ensaio para as reflexões necessárias. Sabemos que o currículo é um campo de intenso duelo. É um espaço de lutas e enfrentamentos. É um território de disputas, na interpretação de Arroyo (2013), por exemplo. É lugar de batalhas de projetos políticos e sociais, como defendem Moreira e Silva (2000); espaço de invenção, criação e representação do mundo, como defendem Monteiro e Gabriel (2014). 0 currículo, portanto, não é apenas lugar de disputas por seleção de conteúdos e metodologias de ensino, mas "[... uma opção cultural, um projeto seletivo de cultura, uma seleção cultural de determinados grupos." (FONSECA, 2008, p. १८).

0 ensino de História, como objeto de preocupação e análise da ciência histórica, encontra-se imbricado com as relações tecidas no tempo. Os usos que se faz da História, por meio de seu ensino, encontram-se intimamente ligados com as diferentes leituras interpretativas que os homens elaboram sobre seu tempo. ${ }^{6}$ Leituras que, por conseguinte, oferecem uma dada orientação nas diferentes formas de agir e atuar no espaço político. Assim, decide-se o que ensinar, como ensinar e para quem ensinar. Essas decisões são fabricadas nas relações de poder que os homens tecem no e com o tempo.

Os enfrentamentos sobre quais temáticas estudar e como estudá-las ocorrem não apenas no campo estrito da ciência histórica. Eles se intensificaram - e persistem atualmente - quando o ensino de História passou a ser um instrumento formal da educação como política de Estado. No Brasil (mas não só no País), em diferentes momentos o ensino de

\footnotetext{
0 historiador Albuquerque (2012) mostra a forma com que a História serviu a diferentes sujeitos, projetos e interesses em distintos tempos e espaços.
} 
História foi e continua sendo um campo de lutas e debates entre plataformas políticas que disputam o controle ou a condução de projetos de sociedades (MATHIAS, 2011). São bastante significativos os embates que ocorreram acerca da retirada da obrigatoriedade do ensino de História no ensino médio. Enfrentamentos que se desdobram de maneira intensa também na redação da Base Nacional Comum Curricular (BNCC).

\section{SITUANDO A PESQUISA}

As reflexões aqui apresentadas são resultantes do projeto Ensino de História, Livro Didático e Formação Docente: entre práticas e representações. 0 projeto se dedica a analisar as matrizes curriculares das licenciaturas em História, oferecidas nas universidades federais do Brasil, para compreender como as discussões sobre ensino de História, livro didático e formação docente são problematizadas durante a formação inicial dos professores. Iniciei a pesquisa pelas universidades localizadas nas regiões Norte e Nordeste. Para este texto, as reflexões se concentram apenas nas matrizes curriculares das licenciaturas das universidades federais da região amazônica do Brasil; portanto, a Universidade Federal de Mato Grosso (UFMT) foi incluída nessa amostragem.

Os documentos das referidas matrizes curriculares foram acessados e salvos na primeira etapa do projeto, que teve início no segundo semestre de 2016, com exceção da Universidade Federal do Oeste do Pará (Ufopa), cujo curso foi criado no segundo semestre, em 2018. Portanto, é possível que algumas matrizes possam ter sofrido alterações nesse intervalo de tempo. As matrizes curriculares aqui analisadas são ofertadas nas sedes das respectivas instituições, com exceção da Universidade Federal do Tocantins (UFT), cuja matriz é do curso ofertado em Porto Nacional.

A primeira fase dessa parte da pesquisa consistiu em fazer um levantamento sobre quantas e quais instituições federais oferecem o curso de Licenciatura em História, bem como entender onde estão localizados geograficamente esses cursos. Em todos os estados que compõem a região amazônica, ao menos uma instituição oferece o Curso de Licenciatura em História. Nesses termos, temos as seguintes instituições: Universidade Federal do Amazonas (Ufam), Universidade Federal do Acre (Ufac), Universidade Federal do Amapá (Unifap), Universidade Federal do Pará (UFPA), Universidade Federal do Sul e Sudeste do Pará (Unifesspa), Universidade Federal do Oeste do Pará (Ufopa), Universidade Federal de Rondônia (Unir), Universidade Federal de Roraima (UFRR), Universidade Federal de Tocantis (UFT), Universidade Federal de Mato Grosso (UFMT) e Universidade Federal do Maranhão (UFMA). 
Após esse primeiro levantamento, iniciamos o processo de busca das matrizes curriculares das referidas instituições. Entre as instituições pesquisadas, nem todas disponibilizam as referidas matrizes nos sites das faculdades e/ou dos institutos, como é o caso da Ufam e da Ufac. 0 acesso a esses documentos ocorreu graças à ajuda de amigos(as) professores(as) que atuam nessas instituições e nos disponibilizaram os documentos.

Para atender aos objetivos do presente artigo, um dos critérios utilizados foi identificar, nas matrizes curriculares dos cursos, quantas e quais disciplinas obrigatórias eram oferecidas para debater as reflexões sobre aprendizagem, de maneira geral, e aprendizagem e Educação Histórica, de maneira mais específica. 0 passo seguinte foi analisar o lugar que ocupa(m) o(s) componente(s) curricular(es) na matriz de cada curso, sua carga horária, sua ementa, seus objetivos e suas referências bibliográficas.

A proposta de análise deste artigo se coaduna com o objetivo maior do projeto de pesquisa ao qual este texto se vincula. Em outras palavras, essas reflexões se encontram no movimento de análise que objetiva compreender como as matrizes curriculares dos cursos de licenciatura em História, oferecidos nas universidades federais do Brasil, enfrentam o debate sobre o ensino dessa disciplina, o livro didático e a formação docente. Esta pesquisa vem permitindo construir uma espécie de cartografia sobre como o ensino de História aparece nas matrizes curriculares dos cursos em que atuamos. Também é possível perceber como esses cursos dividem as temáticas trabalhadas e selecionam o sequenciamento para cada "tema". Demonstra, também, o que se considera obrigatório e optativo em termos de estudos para a formação dos professores que atuarão na educação básica.

\section{AS REFLEXÕES SOBRE APRENDIZAGEM E EDUCAÇÃO HISTÓRICA NAS MATRIZES CURRICULARES}

0 que se ensina, atualmente, nos cursos de licenciatura em História? Essa pergunta, aparentemente banal, pode esconder um universo bastante complexo no exercício da profissão de docentes que atuam na formação de professores que estarão atuando na formação social, política e histórica dos jovens que estão na educação básica. Quais temáticas são priorizadas, quais são silenciadas, quais são exigidas como necessárias para a formação do(a) professor(a) de História de acordo com a matrizes analisadas?

Todavia, gostaria de ressaltar que não compreendo que exista qualquer elemento que condicione uma relação mecânica entre o que se encontra escrito e prescrito nas matrizes e sua aplicabilidade. Não existe força que estabeleça uma exequibilidade entre os enunciados das ementas e sua execução pelo docente responsável por ela. Entre o que está 
prescrito e o que é experienciado existe um universo de tensões, negociações e arranjos que promovem outras configurações para as disciplinas. Há muitas práticas desenvolvidas que não se encontram descritas nos documentos. Há muitos sujeitos atuando nesse palco, e a encenação não segue a determinação irrestrita do roteiro oficial prescrito. Portanto, essas matrizes precisam ser pensadas como vestígios, como indícios de um universo tenso, denso e complexo de questões em permanentes disputas e metamorfoses.

Isso não significa, entretanto, que devemos diminuir a importância das matrizes curriculares e dos discursos que se encontram registrados em seus ementários. Não. As matrizes demonstram e dão a ver uma interpretação acerca do entendimento da História como ciência, como lugar de formação docente. Permitem compreender como os docentes que atuaram na construção de cada uma delas entendiam - e entendem - o que deve ser importante para os profissionais que se formam professores(as) de História.

Nesse movimento de reflexão, podemos questionar, portanto, como se encontram configuradas as matrizes curriculares das licenciaturas em História no que tange à oferta de disciplinas por temáticas de estudo em cada período da graduação? Essa pergunta pode levantar reflexões e contribuir para entendermos o que tem sido priorizado como objeto de estudo e ensino nos cursos de licenciatura em História. Por conseguinte, pode levantar questionamentos para ampliar nossas interpretações sobre as relações de poder que selecionam e definem as temáticas de estudo, no tempo presente, nos espaços de formação docente.

Como qualquer outro documento, as matrizes curriculares necessitam ser criteriosa e cuidadosamente analisadas. Esses documentos se constituem em uma espécie de "DNA" dos cursos e departamentos de História nas universidades do Brasil. Essas matrizes representam um conjunto de discursos e práticas que caracterizam a forma de se fazer História como ciência em nossas universidades. Oferecem e dão a ler uma dada configuração que as licenciaturas em História adquiriram. Demonstram a concepção de História por meio de seus enunciados, suas disciplinas e seus ementários. Expressam suas filiações teóricas e conceituais. Sinalizam aproximações e distanciamentos com variadas acepções de História. Indicam o que consideram importante na formação dos graduados em História. Informam quais questões são obrigatórias para o profissional da área e quais questões são optativas. Apresentam as diferentes acepções das categorias analíticas que formam essa ciência, como "narrativa”, "documento", “fato/acontecimento", "tempo" (para citar apenas algumas).

As matrizes curriculares revelam, também, a distribuição dos conteúdos oferecidos em cada período da formação inicial do professor de História. Por conseguinte, quando oferecem as disciplinas obrigatórias, com suas respectivas cargas horárias, também apresentam quais temáticas são vivenciadas em cada momento e qual o tempo destinado ao estudo de cada temática. 
A configuração temática das matrizes analisadas encontra-se estruturada por meio da divisão clássica da História em quatro períodos. A Tabela 1 apresenta um panorama no que tange à carga horária e à distribuição do número de disciplinas ligadas à chamada História Antiga, Medieval, Moderna e Contemporânea nos cursos analisados.

Tabela 1 - Panorama do arranjo curricular das matrizes curriculares

\begin{tabular}{|c|c|c|c|c|c|c|}
\hline \multirow{2}{*}{$\begin{array}{l}\text { Instituição (ano de } \\
\text { aprovação do PPC) }\end{array}$} & \multirow{2}{*}{$\begin{array}{l}\text { Carga horária } \\
\text { total (horas) }\end{array}$} & \multicolumn{5}{|c|}{ Número de disciplinas } \\
\hline & & Total & $\begin{array}{l}\text { História } \\
\text { Antiga }\end{array}$ & $\begin{array}{l}\text { História } \\
\text { Medieval }\end{array}$ & $\begin{array}{l}\text { História } \\
\text { Moderna }\end{array}$ & $\begin{array}{c}\text { História } \\
\text { Contemporânea }\end{array}$ \\
\hline Ufam, 2006 & 2.865 & 41 & 1 & 2 & 1 & 2 \\
\hline Unifap, 2007 & 3.420 & 44 & 2 & 1 & 2 & 2 \\
\hline UFMT 2009 & 3.268 & 39 & 2 & 2 & 2 & 2 \\
\hline UPPA, 2011 & 3.260 & 45 & 1 & 1 & 1 & 3 \\
\hline UFT, 2011 & 2.805 & 36 & 1 & 1 & 1 & 2 \\
\hline UFRR, 2012 & 2.810 & 38 & 1 & 1 & 1 & 2 \\
\hline Ufac, 2013 & 2.930 & 39 & 1 & 1 & 1 & 2 \\
\hline UFMA 2014 & 2.865 & 36 & 1 & 1 & 2 & 2 \\
\hline Unir, 2014 & 3.560 & 32 & 1 & 1 & 1 & 2 \\
\hline Unifesspa, 2017 & 3.216 & 45 & 1 & 1 & 2 & 2 \\
\hline Ufopa, 2018 & 3.470 & 37 & 1 & 1 & 1 & 2 \\
\hline Total & 34.469 & 432 & १३ & १३ & 15 & 23 \\
\hline
\end{tabular}

Fonte: o autor.

Essas informações permitem compreender uma dada configuração curricular que os cursos de licenciatura em História adquiriram nas últimas duas décadas. Essa leitura permite, igualmente, entender quais passados são mobilizados, no presente, em termos de oferta de disciplinas. lgualmente temos acesso às temáticas que são ensinadas nas disciplinas obrigatórias dos graduandos em História.

A oferta de uma disciplina obrigatória tem implicações de ordem e perspectivas diversas. A começar pela carga horária destinada ao componente curricular. Por essa perspectiva de análise, significa reconhecer quanto de tempo - em termos de horas para as discussões - cada matriz curricular selecionou para as temáticas estudadas em cada disciplina. Do ponto de vista cronológico, instaura-se um determinado tempo para possibilitar o debate, a discussão e a produção de conhecimento sobre cada temática. 
Como já sinalizado (ver Tabela 1), as matrizes analisadas, em larga medida, organizam-se em termos de oferta de disciplinas por meio do modelo quadripartite europeu. Ao refinarmos a busca nas referidas matrizes sobre quais componentes curriculares se encarregam especificamente das reflexões sobre a "aprendizagem histórica", como categoria conceitual/anal'tica fundamentada na ciência histórica, por exemplo, os resultados não são nada animadores.

Das 11 licenciaturas pesquisadas, apenas uma oferece uma disciplina obrigatória, com objetivos e referências bibliográficas que tematizam a aprendizagem histórica, problematizada por meio da educação histórica, que compreende uma categoria e um campo pertencentes à História como ciência de referência. Nesse sentido, podemos afirmar que o Curso de História da Unifesspa é o único curso de licenciatura em História oferecido nos campi-sede das universidades federais que compõem a região amazônica.

A matriz curricular do Curso de História da Unifesspa define que a construção da Educação Histórica se encontra entre as habilidades e competências instituídas nesse curso. Nesses termos, esse documento assevera que o Curso de Licenciatura em História deve

\footnotetext{
Refletir sobre as questões educacionais e pedagógicas referentes ao ensino da História nos níveis Fundamental, Médio e Educação de Jovens a Adultos (EJA) de forma a propor projetos de intervenção na realidade escolar, capazes de permitir a educação histórica do cidadão. (UNIVERSIDADE FEDERAL DO SUL E SUDESTE DO PARÁ, 2018, p. 30).
}

A disciplina voltada a dar conta dessa competência é "Didática e Educação Histórica" que, de acordo com sua ementa, propõe-se à seguinte análise:

\begin{abstract}
Educação histórica como forma de pensar a relação do ensino com a produção de conhecimento historiográfico, articulado na ação efetiva entre o conhecimento históricos como a ciência especializada. 0 aprendizado histórico a partir das experiências e identidades dos sujeitos em seu contexto sócio cultural, como um processo para ensinar e aprender História no cotidiano e da tomada de consciência historiográfica, como elemento essencial na formação do aluno de História. (UNIVERSIDADE FEDERAL DO SUL E SUDESTE DO PARÁ, 2018, p. 60).
\end{abstract}

A constatação de que apenas uma das instituições apresenta reflexões sobre a aprendizagem histórica e/ou educação histórica não significa que as demais ignorem as questões que envolvem o processo de aprendizagem entre seus graduandos. Mesmo não pautando a aprendizagem histórica, a problematização sobre aprendizagem - de forma geral - aparece na disciplina de "Psicologia da Educação" e/ou, em menor número, na disciplina denominada "Didática”. 
De acordo com as matrizes curriculares, com exceção do curso oferecido na Unifesspa, todas as demais alocam as reflexões sobre aprendizagem no componente curricular denominado "Psicologia da Educação". Ou seja, 10 das 11 matrizes aqui analisadas entendem que as análises que envolvem aprendizagem devem ser experienciadas pelas reflexões promovidas pela "área" da Psicologia. Do total de 10 cursos, sete também abrem espaço para o debate sobre aprendizagem em outro componente curricular denominado “Didática”. Em menor número, o debate sobre aprendizagem também aparece nas disciplinas de "Estágio Supervisionado" e "Metodologia e Prática de Ensino". A Tabela 2 ajuda a visualizar o panorama da distribuição da temática "aprendizagem" entre os componentes curriculares e suas respectivas instituições.

Tabela 2 - Relação das disciplinas sobre Aprendizagem

\begin{tabular}{llr}
\hline \multicolumn{1}{c}{$\begin{array}{c}\text { Disciplinas obrigatórias que abordam } \\
\text { aprendizagem }\end{array}$} & \multicolumn{1}{c}{ Relação das Instituições (siglas) } & Total \\
\hline Psicologia da Educação & $\begin{array}{l}\text { Ufam, Unifap, UFMT, UFPA, UFT, UFRR, Ufac, UFMA, Unir, } \\
\text { Ufopa. }\end{array}$ & 10 \\
Didática & Ufam, UFMT, UFT, UFRR, Ufac, Unir, Ufopa. & 7 \\
Estágio Supervisionado & Ufam, UFPA, Ufac, Ufopa. & 4 \\
Metodologia e Ensino de História & Unifap, UFT. & 2 \\
Práticas de Ensino & UFPA, Ufac. & 2 \\
Didática da História ou Educação Histórica & Unifesspa. & 1 \\
\hline
\end{tabular}

Fonte: o autor.

Para os profissionais formados na Ufam, os debates sobre aprendizagem são experienciados em três disciplinas. "Psicologia da Educação", "Didática” e "Estágio Supervisionado". De acordo com a ementa da disciplina "Psicologia da Educação", as reflexões desse componente deverão se pautar na "[...] aprendizagem como processo e como atividade." (UNIVERSIDADE FEDERAL DO AMAZONAS, 2006, p. 33). Na disciplina “Didática Geral”, os graduandos também devem refletir sobre a aprendizagem. Segundo sua ementa, o componente se dedica a refletir sobre "[...] contextualização histórico-social da educação e da didática. Concepções didático-pedagógicas e suas implicações no processo ensino-aprendizagem. Planejamento educacional (níveis, etapas, tipos, componentes)." (UNIVERSIDADE FEDERAL DO AMAZONAS, 2006, p. 35, grifo nosso).

A temática do ensino e da aprendizagem também consta como objetivo de estudo nas ementas das quatro disciplinas de estágio supervisionado dessa lnstituição. 
0 processo de "ensino e aprendizagem" é o tema/objeto de reflexão nos componentes curriculares ofertados na Unifap e na UFMT na disciplina "Psicologia da Educação". Na Unifap, a disciplina, com carga horária de 60 horas-aulas, propõe-se a refletir sobre "História, campos e ramos da psicologia. Desenvolvimento biopsicossocial e cognitivo da infância e da adolescência e suas implicações no processo de ensino aprendizagem." (UNIVERSIDADE FEDERAL D0 AMAPÁ, 2007, p. 62). Ofertada pelo departamento de Psicologia, a disciplina, na UFMT (também com carga horária de 60 horas-aulas), tem como objetivos de estudo refletir sobre a “[...] compreensão do processo da aprendizagem e suas contribuições para o ensino. [...] Psicologia da Aprendizagem: Conceitos fundamentais e princípios nas diversas correntes de aprendizagem e suas contribuições para a Educação Escolar." (UNIVERSIDADE FEDERAL DO MATO GROSSO, 2014, p. 63).

Nessa mesma Instituição, ainda há a disciplina "Didática para o Ensino de História", na qual o foco também recai sobre os fundamentos teóricos do processo de ensino e aprendizagem, pautado nas reflexões sobre metodologia do ensino de História. As referências desse componente curricular variam entre autores do campo da educação e da metodologia do ensino de história.

0 binômio ensino e aprendizagem - ora escrito "ensino-aprendizagem" - é a tônica que permeia todos os componentes curriculares das 10 instituições pesquisadas. Em alguns casos, ocorre alguma variação no título do componente curricular e nos enunciados das ementas. Mas, em linhas gerais, as disciplinas se propõem a refletir o processo do que consideram como ensino e aprendizagem.

Quando analisamos o texto das matrizes curriculares, em diversas passagens encontramos discussões que ressaltam a importância de focar no processo de ensino e aprendizagem durante a formação inicial de seus profissionais. No entanto, essas questões não aparecem nas ementas dos componentes curriculares dos cursos analisados. Ou seja, expressase como sendo importante e necessária a reflexão sobre ensino e aprendizagem, mas não se identificam, na redação dos ementários, sinais que apontem essa preocupação. As disciplinas de conteúdos específicos do campo historiográfico, por exemplo, não demonstram indícios de que as reflexões das temáticas estudadas nesses componentes dialogam com as questões sobre o ensino e a aprendizagem de cada tema trabalhado nesses respectivos componentes.

\section{O QUE DEUEM LER OS FUTUROS PROFESSORES DE HISTÓRIA}

A análise atenta das matrizes curriculares das licenciaturas em História oferece muitas reflexões. Permite a construção de uma radiografia dos cursos nos quais atuamos e 
formamos os futuros professores de História das escolas públicas e privadas. Uma radiografia sobre como se configura essa ciência, esse lugar de saber/poder. Sobre como organiza seus conteúdos, suas cargas horárias, suas temáticas de estudo, suas seleções em termos de atividades obrigatórias e optativas. Da mesma forma, demonstra o que essa ciência - com toda sua polifonia de sentidos e significados - seleciona como referências obrigatórias em termos de leituras para os profissionais que nela se formam.

Nesses termos, podemos problematizar o que as matrizes analisadas instituem como leitura obrigatória para seus componentes curriculares. Ou seja, o que devem ler os profissionais formados nessa área sobre cada temática de estudo? Quais os livros e os autores que aparecem na bibliografia básica das disciplinas e que significados emitem essas referências? Portanto, é importante compreender e refletir acerca das indicações bibliográficas que os componentes curriculares analisados apresentam. As ementas dividem as indicações bibliográficas entre duas categorias: bibliografia básica e complementar. Para as análises aqui desenvolvidas, estou considerando apenas os autores e as obras presentes na primeira categoria.

Uma leitura comum a todas as disciplinas aqui analisadas é que não há referências bibliográficas sobre "aprendizagem" de autoria do campo da ciência de referência. A exceção é a disciplina ofertada na Unifesspa, que define a "aprendizagem histórica" como objeto de estudo e tem como autores, na bibliografia básica, Jörn Rüsen, Maria Auxiliadora Schmidt, Ana Claudia Urban e Luis Fernando Cerri. Para as demais instituições, 10 de um total de 11, as indicações de leitura são predominantemente da Psicologia e da Educação. Quando se discute "ensino e aprendizagem", nas ementas das disciplinas de Psicologia da Educação, os referenciais são de autores do campo da Psicologia. Quando aparece menção ao "ensino e aprendizagem" nas disciplinas de "Didática", as referências são, em sua maioria, da área da Educação. Quando esse debate é alocado como tema de estudo nas disciplinas de "Metodologia do Ensino de História", aparecem autoras da área da História, como Circe Bittencourt e Selva Guimarães Fonseca.

Essa diversidade de referências e de lugares onde aparecem as temáticas sobre aprendizagem pode ser entendida de diferentes maneiras. Certamente representam um indício de como os professores historiadores que atuam nas licenciaturas apreendem e atribuem significado ao que entendem por aprendizagem histórica. 0 escasso debate na ciência de referência sobre aprendizagem histórica acompanha o processo de institucionalização dessa área e talvez também concorra como força que contribui para que sejam atribuídas a outras áreas as discussões sobre aprendizagem. Nessa dimensão, Schmidt (2014, p. 37) ressalta que "[...] nesse processo, as questões relacionadas à aprendizagem histórica e, portanto, ao seu ensino, saíram da pauta dos historiadores e entraram, prioritariamente, na pauta das teorias educacionais e, portanto, das formas e funções da escolarização." Essa interpretação talvez contribua para entender por que, em algumas matrizes curriculares, o debate é pensado 
como sendo do campo da Psicologia e da Educação. Ao passo que, em outros cursos, as reflexões aparecem como sendo uma questão de metodologia de ensino. Nesses casos, as referências bibliográficas indicam que o debate deve ser conduzido pelas reflexões também do campo da Educação.

Essa configuração pode servir de indício para refletirmos como a ciência histórica tem enfrentado a problematização acerca da aprendizagem histórica. A começar pela ausência, quase que absoluta, de componentes curriculares para debater a aprendizagem histórica como objeto de interesse da História como ciência. Essa ausência diz muito. Sugere que não fazem parte dos interesses dessa ciência as reflexões sobre como se aprende historicamente. Como nós, sujeitos históricos, aprendemos a pensar, entender e interpretar historicamente? Quais capacidades cognitivas necessitamos para pensar e aprender historicamente? Aprender história é análogo a aprender outra área do conhecimento?

A escassez dessas reflexões dentro da ciência de referência talvez explique por que as disciplinas voltadas ao debate sobre aprendizagem não tematizam as singularidades da aprendizagem histórica. Por conseguinte, a ausência de estudos sobre aprendizagem histórica pela ciência de referência pode contribuir para explicar porque as licenciaturas estudadas mencionam de forma genérica a "aprendizagem" e, em suas disciplinas, delegam a reflexão para outras áreas do conhecimento. 0 problema não reside em dialogar com a Psicologia ou com a Educação, diga-se à exaustão. 0 problema, a meu ver, reside no abandono dessas reflexões por parte da ciência de referência.

Essas reflexões também sinalizam o que os professores de História, em sua formação inicial, "devem" aprender na concepção dos autores de cada PPC. Um olhar atento para a configuração das matrizes curriculares das licenciaturas permite identificar um arranjo de saberes, conceitos e representações sobre os sentidos acerca da História como ciência, como lugar de formação de professores.

As matrizes curriculares dos cursos indicam, portanto, como a ciência histórica deve se compor em termos de seleção de conteúdos. Apontam o encadeamento das discussões e o sequenciamento dos temas de estudo por períodos. As matrizes também mostram como a ciência histórica é configurada por meio de suas disciplinas, a partir daquilo que apresentam como sendo necessário para as temáticas de estudo. Direcionam o que deve ser estudado e aprendido em cada etapa do processo de formação dos graduandos.

A professora Caimi (2015), ao analisar o processo de formação docente dos professores de História, chama a atenção para a importância de se construirem outras habilidades além daquelas necessárias ao domínio dos conteúdos. Nessa perspectiva, ela defende que "[...] para se ensinar História a João é preciso entender de ensinar, de História e 
de João." (CAIMl, 2015, p. 111). No entanto, ao analisarmos as matrizes curriculares, é possível perceber que essa preocupação ainda não se encontra naqueles documentos.

Ao analisar as temáticas presentes nas demais ementas das matrizes curriculares até o momento analisadas, percebe-se uma completa ausência do debate sobre a aprendizagem histórica e sobre o ensino de História. Os objetivos de estudo registrados nos ementários mencionam apenas os conteúdos a serem ensinados aos futuros professores. Não há nenhuma menção sobre o processo cognitivo de aprendizagem histórica. Predomina uma absoluta ausência no que tange às reflexões que envolvem as diferentes capacidades cognitivas pelas quais se aprende e se ensina História. Nada é mencionado acerca de como os conteúdos expostos nas ementas podem ser trabalhados na educação básica, haja vista ser esse o espaço de atuação onde vai trabalhar aquele profissional que está sendo formado. Há um silêncio estarrecedor sobre o ensino de História, a aprendizagem histórica e, igualmente, sobre as singularidades dos jovens a quem os futuros professores irão ensinar.

A ausência dessas problemáticas de estudo pode sugerir, portanto, que no entender dos docentes responsáveis pela construção das matrizes curriculares o debate sobre aprendizagem histórica e o ensino da própria área não é importante. Em outras palavras, a permanência dessas lacunas também pode indicar que, para uma parte dos professores formadores que atua nos respectivos cursos analisados, os conhecimentos sobre os conteúdos a serem trabalhados em sala de aula bastam para a formação do professor de História.

Não podemos perder de vista que estamos analisando as matrizes curriculares das licenciaturas em que estão sendo formados os professores de História para atuar na educação básica. Pela leitura das matrizes curriculares, não seria inverossímil afirmar que, para que o futuro professor possa dar aula de História, é suficiente que ele conheça o conteúdo a ser ministrado, haja vista que as ementas não propõem nenhuma reflexão sobre o ensino de História e/ou a metodologia do ensino de História.

Não disponho, até o momento da pesquisa, de elementos que permitam entender as condições que possibilitaram a inserção dos temas selecionados como objeto de reflexão nos referidos componentes curriculares. Da mesma forma, também ainda não é possível afirmar os motivos pelos quais predomina uma ausência quase que absoluta sobre as reflexões que envolvem o ensino de História das disciplinas analisadas. ${ }^{7}$

Entretanto, podemos afirmar que a inserção ou supressão de uma temática de estudo pode estar relacionada com a sensibilidade do(s) docente(s) envolvido(s) no processo de construção da referida matriz curricular e com as relações de poder praticadas dentro de cada espaço onde as matrizes são construídas. Pois de nada adianta ter docentes

\footnotetext{
Em uma etapa posterior da pesquisa, pretendo entrevistar alguns professores responsáveis pela construção das matrizes curriculares, momento em que, certamente, essa e outras questões poderão ser esclarecidas.
} 
sensibilizados pela importância do debate sobre a aprendizagem histórica e o ensino de História se, no departamento no qual ele atua, não há espaço que garanta a inserção dos debates dentro das matrizes.

É importante mencionar que os PPCs não são documentos estanques. Sofrem alterações de diferentes naturezas e direcionamentos, como aquelas estabelecidas pelo Conselho Nacional de Educação/Ministério da Educação (CNE/MEC), ao definir um número mínimo de horas-aulas para as atividades de prática curricular e estágios. Da mesma forma, as matrizes curriculares também são alteradas pelas mudanças realizadas pelo corpo docente, que desfruta de uma relativa autonomia para propor e executar as alterações.

Apesar desses campos de forças que permitem mudanças nos PPCs, os cursos analisados ainda estruturam suas matrizes curriculares por meio da divisão clássica da História entre Antiga, Medieval, Moderna e Contemporânea. Vale ressaltar, todavia, que existem outros componentes curriculares que estão distribuídos entre os períodos das licenciaturas. São disciplinas com temáticas variadas, que versam sobre teoria, história da América, história do Brasil, ${ }^{8}$ história dos estados onde são oferecidas as licenciaturas. Em menor frequência, também se identificam componentes curriculares sobre a história da África e o ensino de História.

\section{CONSIDERAÇÕES FINAIS}

Por que os cursos de licenciatura em História selecionam as temáticas presentes em cada disciplina? Por que continuamos a ensinar o que ensinamos? A quem realmente interessa a permanência das temáticas obrigatórias estudadas no período de formação inicial do professor? Por que continuamos a ensinar, nos cursos, uma História predominantemente europeia?

A partir das disciplinas e suas respectivas ementas, é possível afirmar que nos cursos de licenciatura na região Amazônica - e, quiçá, no Brasil -, a questão sobre aprendizagem não diz respeito à História como ciência. Talvez seja esse o motivo pelo qual o debate sobre "aprendizagem histórica" praticamente inexista nas graduações; ao menos não se encontram nos documentos prescritos. Talvez seja essa a razão pela qual as reflexões sobre "aprendizagem em geral" sejam atribuídas às disciplinas de outras áreas do conhecimento, oferecidas em outros departamentos.

Percebe-se que as ementas priorizam, essencialmente, a exposição de conteúdos como elemento central na formação dos futuros profissionais formados nessa ciência. 0 foco 
das disciplinas, ao que parece, é efetivamente a transmissão do conteúdo. Pelos ementários das matrizes analisadas, percebe-se uma formação profissional centrada nos conteúdos e voltada, predominantemente, para o passado longínquo. Dito de outra forma, as matrizes apresentam as temáticas de estudos sem oferecer indícios que permitam perceber relações com o presente. Ou seja, os passados são apresentados como conteúdos distantes no tempo e no espaço, sem conexão com o presente; um passado apenas passado e não um passado como invenção do presente.

\section{REFERÊNCIAS}

ALBUQUERQUE JÚNIOR, D. M. de. Fazer defeitos nas memórias: para que servem o ensino e a escrita da história? In: GONÇALVES, M. de A. et al. (org.). Qual o valor da História Hoje? Rio de Janeiro: Editora FGV, 2012. p. 21-39.

ARROYO, M. G. Currículo, território em disputa. 5. ed. Petrópolis, RJ: Vozes, 2013.

BARCA, I. Literacia e consciência histórica. Educar em Revista, n. 164, p. 93-112, 2006. Número Especial.

CAIM, F. E. 0 que precisa saber um professor de história? Revista História \& Ensino, v. 21, n. 2, p. 105१२४, 2015.

CAVALCANTI, E. A história encastelada e o ensino encurralado: re $\unrhd$ exões sobre a formação docente dos professores de história. Educar em Revista, v. 34, n. 72, p. 249-267, nov./dez. 2018a.

CAVALCANTI, E. Ensino de história, livro didático e formação docente de professores de História no Brasil. Revista Enseñanza de las Ciencias Sociales, n. 18, p. 49-61, 2019.

CAVALCANTI, E. História, ensino de história e livro didático: a formação docente em debate. Sæculum Revista de História, v. 38, jan./jun. 2018b.

EVANGELISTA, 0.; TRICHES, J. Ensino de história, didática de história, educação histórica: alguns dados de pesquisa (2000-2005). Educar em Revista, p. 33-55, 2006. Edição Especial.

FONSECA, S. G. A formação de professores de história no Brasil: perspectivas desafiadoras de nosso tempo. In: ZAMBONI, E.; FONSECA, S. G. (org.). Espaço de formação do professor de história. Campinas, SP: Papirus, 2008.

GONZALEZ, M. P. Los profesores y la transmisión de la historia argentina reciente: entre el currículum y el contexto. Práxis Educativa, v. 3 n. 1, p. 17-28, 2008.

MATHIAS, C. L. K. 0 ensino de história no Brasil: contextualização e abordagem historiográfica. História Unisinos, n. 15, v. 1, p. 40-49, 2011. 
MELO, M. do C. de. A formação de professores de história em Portugal: práticas pedagógicas e investigativas. Revista História Hoje, v. 4, n. 7, 41-61, 2015.

MONTEIRO, A. M. Formação de professores: entre demandas e projetos. Revista História Hoje, v. 2, n. 3, p. 19-42, 2013.

MONTERO, A. M. Professores de história: entre saberes saberes e práticas. Rio de Janeiro: Mauad X, 2007.

MONTEIRO, A. M.; GABRIEL, C. T. Currículo de história e narrativa: desafios epistemológicos e apostas políticas. In: MONTEIRO, A. M. et al. Pesquisa em ensino de história: entre desafios epistemológicos e apostas políticas. Rio de Janeiro: Mauad X; Faperj, 2014.

MONTEIRO, F. G. da C.; ROCHA, V. S. A formação do professor de história e os desafios contemporâneos. História \& Ensino, v. 21, n. 2, p. 307-324, 2015.

MOREIRA, A. F. B.; SILVA, T. T. Currículo, cultura e sociedade. São Paulo: Cortez, 2000.

OLIVEIRA, M. D. de; CAINELLI, M. R.; OLIVEIRA, A. F. B. de. Ensino de história: múltiplos ensinos em múltiplos espaços. Natal: EdUFRN, 2008.

PAGĖS, J. Enseñar a enseñar Historia: la formación didáctica de los futuros profesores. In: GÓMEZ, J. A.; NICOLÁS, M. E. (coord.). Miradas a la Historia: reflexiones historiográficas en recuerdo de Miguel Rodríguez Llopis. Murcia: Universidad de Murcia, Servicio de Publicaciones, 2004. p. 155-178.

PEREIRA, N. M.; SEFFNER, F. 0 que pode o ensino de história? Sobre o uso de fontes na sala de aula. Anos 90, v. 15, n. 28, p.113-128, 2008.

RAMOS, M. E. T.; CAINELLI, M. R. A educação histórica como campo investigativo. Diálogos, v. 19, n. 1, p. $11-27,2015$.

ROCHA, H.; REZNIK, L.; MAGALHÃES, M. de S. (org.). Livros didáticos de história: entre políticas e narrativas. Rio de Janeiro: FGV, 2017.

RODRÍGUEZ, M. V. Políticas de formação de professores: as experiências de formação inicial em Argentina, Chile e Uruguai. Nuances: estudos sobre Educação, v. 15, n. 16, p. 119-139, 2008.

RÜSEN, J. Aprendizado histórico. In: SCHMIDT, M. A.; BARCA, l.; MARTINS, E. de R. (org.). Jörn Rüsen e o ensino de história. Curitiba: Editora da UFPR, 2011a. p. 41-78.

RÜSEN, J. Aprendizagem histórica. Fundamentos e paradigmas. Curitiba: W \& A Editores, 2012.

RÜSEN, J. Didática da história: passado, presente e perspectivas a partir do caso alemão. In: SCHMDT, M. A.; BARCA, l.; MARTINS, E. de R. (org.). Jörn Rüsen e o ensino de história. Curitiba: Editora da UFPR, 201lb. 
RÜSEN, J. Experiência, interpretação, orientação: as três dimensões da aprendizagem histórica. In: SCHMDT, M. A.; BARCA, l.; MARTINS, E. de R. (org.). Jörn Rüsen e o ensino de história. Curitiba: Editora da UFPR, 2011c. p. 78-92.

RÜSEN, J. História viva: teoria da história III - formas e funções do conhecimento histórico. Tradução: Estevão de Rezende Martins. Brasilia, DF: Editora da Universidade de Brasília, 2010.

RÜSEN, J. Teoria da história: uma teoria da história como ciência. Curitiba: Editora da UFPR, 2015.

SCHMIDT, M. A.; BARCA, I.; MARTINS, E. de R. (org.). Jörn Rüsen e o ensino de história. Curitiba: Editora da UFPR, 2011.

SCHMDT, M. A.; CAINELLI, M. A consciência histórica como o lugar e o propósito da aprendizagem histórica: introdução a um diálogo com a teoria de Jörn Rüsen. In: ZAMBONI, E.; GALZENARI, M. C. B; PACIEVITCH, C. (org.). Memória, sensibilidade e saberes. Rio de Janeiro: Alínea Editora, 2015.

SCHMIDT, M. A. Cultura histórica e aprendizagem histórica. Revista NUPEM, v. 6, n. 10, jan./jun. 2014.

SCHMIDT, M. A.; GARCIA, T. M. B. G. Pesquisas em Educação Histórica:algumas experiências. Educar em Revista, p. 11-31, 2006. Edição Especial.

SCHMDT, M. A. 0 historiador e a pesquisa em educação histórica. Educar em Revista, v. 35, p. 35-53, 2019.

SCHMIDT, M. A. Qué hacen los historiadores cuando enseñan la Historia? Contribuciones de la teoría de Jörn Rüsen para el aprendizaje y el método de enseñanza de la Historia. Clio \& Associados - La historia ensenada, v. 24, p. 26-37, 2017.

SCHMIDT, M. A.; URBAN, A. C. Afinal, o que é Educação Histórica? Revista lbero-americana de Educação Histórica, v. 1, n. 1, p. 31-71, 2018.

SILVA, C. B.; ROSSATO, L. A didática da história e o desafio de ensinar e aprender na formação docente inicial. Revista História Hoje, v. 2, n. 3, p. 65-85, 2013.

SILVA, D. P. 0 lugar do tempo presente na aula de história: limites e possibilidades. Revista Tempo e Argumento, v. 9, n. 20, p. 99-129, 2017.

TARDIF, M. 0 trabalho docente: elementos para uma teoría da docência como profissão de interações humanas. Petrópolis, RJ: Vozes, 2014.

UNIVERSIDADE FEDERAL DE MATO GROSSO. Projeto Poĺtico Pedagógico do Curso de Licenciatura em História. Cuiabá: UFMT, 2009. Disponivel em: http://sistemas.ufmt.br/ufmt.ppc/PlanoPedagogico/Download/१३1. Acesso em: 20 mar. 2019. 
UNIVERSIDADE FEDERAL DE RORAIMA. Projeto Poĺtico Pedagógico do Curso de Licenciatura em História. Boa Vista: UFRR, 2012. Disponivel em: https://www.google.com.br/url?sa=t\&rct=j\&q=\&esrc=s\&source=we $b \& c d=2 \&$ cad=rja\&uact=8\&ved=0ahUKEwiOlubC zZnRAhUETJAKHSqPCwIQFgghMAE\&url=http\%3A\%2F\%2Fufrr. br\%2Fistoria\%2Findex.php\%3Foption\%3Dcom_phocadownload\%26view\%3Dcategory\%26download\%3D50\%3A ppp-curso-de-historia\%26id\%3D2\%3Aresgimento\%26ltemid\%3D201\&usg=AFQjCNHHoCQW7T4Sc8mJbPxFF58kScGcig\&sig2=4z4Wv-0LAGNd-ZNUsxYkmQ\&bvm=bv.142059868,d.Y2l. Acesso em: 30 dez. 2016.

UNIVERSIDADE FEDERAL DO ACRE. Projeto Poĺtico Pedagógico do Curso de Licenciatura em História. Rio Brasil: UFAC, 2013.

UNIVERSIDADE FEDERAL DO AMAPÁ. Projeto Político Pedagógico do Curso de História Licenciatura. Macapá: Unifap, 2007. Disponivel em: http://www2.unifap.br/historia/files/2013/04/licenciaturahistoria. pdf. Acesso em: 30 dez. 2016.

UNIVERSIDADE FEDERAL DO AMAZONAS. Projeto Poĺtico Pedagógico do Curso de Licenciatura em História. Manaus: UFAM, 2006. Disponivel em: https://biblioteca.ufam.edu.br/attachments/article/256/ Projeto\%2OPedagogico\%2OFormatado\%20-\%20Historia\%20Diurno\%20(1)\%20BIB\%20ATUALIZADA.pdf. Acesso em: 30 dez. 2016.

UNIVERSIDADE FEDERAL DO MARANHÃO. Projeto Político Pedagógico do Curso de História. São Luís: UFMA, 2014. Disponivel em: https://sigaa.ufma.br/sigaa/public/curso/ppp_curso.jsf?lc=pt_BR\&lc=pt_ BR\&id=85811.

Acesso em: 15 ago. 2018.

UNIVERSIDADE FEDERAL DO OESTE DO PARÁ. Projeto Poĺtico Pedagógico do Curso de Licenciatura em História. Santarém: UFOPA, 2018. Disponivel em: http://www2.ufopa.edu.br/ufopa/arquivo/proen-cursos-portarias-ppcs/ppc-licenciatura-historia. Acesso em: 23 nov. 2018

UNIVERSIDADE FEDERAL DO PARÁ. Projeto Político Pedagógico do Curso de Licenciatura em História. Belém: UFPA, 2011. Disponivel em: http://www.ufpa.br/historia/projeto\%20pedag\%C3\%B3gico.PDF. Acesso: em 30 dez. 2016.

UNIVERSIDADE FEDERAL DO SUL E SUDESTE DO PARÁ. Projeto Político Pedagógico do Curso de Licenciatura em História. Marabá: Unifesspa, 2018. Disponivel em: https://historia-maraba.unifesspa.edu.br/ images/arquivos/PPC-HISTORIA-2018-ATUALIZAD0.pdf. Acesso em: 23 nov. 2018.

UNIVERSIDADE FEDERAL DO TOCANTINS. Projeto Político Pedagógico do Curso de Licenciatura em História. Porto Nacional: UFT, 2011. Disponível em: http://download.uft.edu.br/?2d=14edae36-efb0-4382-9da7-d8267c9e5cd9. Acesso em: 30 dez. 2016.

Endereço para correspondência: Folha 31, Quadra 07, Lote Especial, s/n., Nova Marabá, Marabá Pará, Brasil; ericontadordehistorias@gmail.com

Roteiro, Joaçaba, U. 45, p. 1-22, jan./dez. 2020 | e21829 |E-ISSN 2177-6059 